\title{
㐘 \\ RELIGIÃO E POLÍTICA: O MUNDO \\ EVANGÉLICO E A GEOGRAFIA DO VOTO
}

- CLEINTON ROBERTO PERPETO DE SOUZA ${ }^{1}$

RESUMO: O INTUITO DO PRESENTE ARTIGO É MENSURAR O PESO ELEITORAL DO CHAMADO "VOTO RELIGIOSO", TENDO COMO OBJETO DE ANÁLISE A ELEIÇÃO DE 2010, QUE FOI MUITO RICA QUANTO A ESTA TEMÁTICA, SERVINDO POR ISSO COMO BASE PARA SE PENSAR TAMBÉM A ELEIÇÃO PRESIDENCIAL SEGUINTE, A DE 2014. A IDEIA CENTRAL É DIFERENCIAR O PESO QUALITATIVO DO PESO QUANTITATIVO DO VOTO RELIGIOSO, UMA VEZ QUE O NÚMERO DE INDIVÍDUOS QUE ATRIBUEM À RELIGIÃO A SUA ESCOLHA ELEITORAL SE MOSTROU MUITO DIFERENTE DO QUE REZA O DISCURSO DE ALGUNS LÍDERES DE SEGMENTOS RELIGIOSOS, SENDO QUE O FOCO AQUI É O DISCURSO ATRELADO AO CHAMADO "VOTO EVANGÉLICO", TÃO VALORIZADO E FORTALECIDO NOS ESPAÇOS RELIGIOSOS, AINDA QUE TÃO POUCO NA ESFERA SECULAR.

PALAVRAS-CHAVE: ELEIÇÕES PRESIDENCIAIS; EVANGÉliCOS; VOTO RELIGIOSO; SILAS MALAFAIA.

\section{Introdução}

Um levantamento histórico sobre a relação entre o voto e a questão religiosa mostra que o fator religião passou a ser respeitado como uma variável explicativa de grande monta. Embora as eleições de 2014 tenham trazido o tema novamente à tona, não o fez com tanta força como aconteceu nas eleições de 2010, quando a peregrinação dos candidatos aos templos religiosos se deu de forma muito mais intensa, fazendo a religião ter um peso qualitativo bastante respeitável no pleito.

Buscando explicação na fala daquele que é considerado o mais influente líder evangélico dos tempos atuais, o pastor Silas Malafaia, da igreja Assembleia de Deus Vitória em Cristo, é possível perceber a força qualitativa daquilo que Albert Hirschman (1992) chama de uma "retórica reacionária da intransigência", algo que se mostra forte o suficiente para fazer com que ESPAÇO E CULTURA, UERJ, RJ, N. 37, P.99-115, JAN./JUN. DE 2015 http://www.e-publicacoes.uerj.br/index.php/espacoecultura/ 
candidatos e partidos alterem agendas, planos de governo e discursos, baseados em falas como as que Malafaia tem proferido em tempos de eleição. As perguntas que ficam, no entanto, são: teria mesmo o voto religioso essa força toda? Teria Silas Malafaia razão no que diz e pensa acerca do voto de seus fiéis seguidores?

A fim de responder a essas questões, é importante começar o presente trabalho com o que de mais atual se pode ter do pastor supracitado - para depois voltar no tempo - lançando assim mão de seus dizeres para a eleição de 2014, quando o tema religião novamente se apresentou e pautou debates, embora não tenha conseguido a força que apresentou em 2010, ano ao qual voltaremos, pois nos servirá mais de base, dados os números e episódios que aquele embate entre Dilma Rousseff e José Serra ofereceu.

Pensando na última eleição, a de 2014, e seguindo os "números" do pastor Malafaia, não se poderia negar a vitória acachapante que teria a candidata Marina Silva, alocada no PSB, ainda que o voto deste senhor - e do segmento que ele acredita que votaria na mesma direção fosse, no primeiro turno, no seu colega pastor Everaldo, do PSC. Os "dados" de Malafaia apontavam para uma situação bastante favorável à Marina Silva, chegando a inspirar as seguintes palavras do pastor:
Não tenho dúvidas:

Marina levará de $80 \%$ a $90 \%$ do voto evangélico. A candidatura dela, o acirramento da propaganda e as redes sociais mudaram tudo. $\mathrm{O}$ evangélico tem interação social, porque vai à igreja pelo menos uma vez por semana. Ninguém usa as redes sociais como os evangélicos, e somos entre $25 \%$ e $27 \%$ da população. Somem a nós os católicos praticantes, também uns $25 \%$ a $27 \%$ e que, em muitos pontos, pensam igual. Já deu a maioria da população. (PARUTY, 2014)

Pelos ditos de Malafaia, então, Marina Silva levaria a eleição com muita tranquilidade, já que a maioria votaria numa candidatura simpática aos pensamentos do líder religioso mais comentado do país. Dizendo-se seguidor de uma ideia do filósofo contemporâneo Michael Sandel, Malafaia defende que "as questões morais e de fé são fundamentais no debate político". Fora isso, é preciso pensar na questão da geografia do voto, já que a interação social proporcionada pelo ir à igreja teria um imenso peso. 
Focando, então, Marina Silva, e não mais o seu principal candidato, pastor Everaldo, Malafaia entende que, apesar de seu colega ter marcado $4 \%$ das intenções de voto, quando do lançamento de sua candidatura, poderia ter chegado a $10 \%$, "bastando o engajamento dos líderes evangélicos", o que levaria para o segundo turno uma agenda bastante voltada à moralidade religiosa, algo que Malafaia entende como fundamental numa eleição. A falta de engajamento da liderança evangélica e a morte trágica do candidato Eduardo Campos teriam sido as responsáveis pela mudança de panorama, invalidando, segundo Malafaia, o projeto evangélico personificado no pastor do PSC. A importância do espaço geográfico se faz muito notória, portanto, já que o que teria feito a candidatura evangélica lograr êxito seria a força dos espaços sagrados, só que, como foi dito por Malafaia, houve falha no “engajamento dos líderes” de tais espaços.

Todavia, seguindo a lógica do pastor Malafaia, ainda que sem Everaldo no embate, restaria ao povo evangélico e aos católicos praticantes, "maioria da população", o voto em Marina Silva, para quem, segundo o líder da Assembleia de Deus Vitória em Cristo, a vitória estava garantida, já que, segundo suas palavras confiantes: "se duvidar, nem vai para o segundo turno. Marina leva logo agora".

Algo aconteceu nos dois caminhos, como ulteriormente se confirmaria, invalidando a vitória de José Serra em 2010 e a de Marina Silva (que nem foi ao segundo turno) em 2014, que é o que se pretende aqui analisar, ainda que sem a paixão de Malafaia, que não teve dificuldades em afirmar: "Marina é candidata do povo e eu interpreto o pensamento dessa maioria".

Como se confirmou pelas urnas, Marina não era a candidata do povo e Silas Malafaia não representava a maioria. Cabe, pois, analisar, à luz do forte acirramento provocado pelo fator religião em 2010, o que estaria por trás das duas derrotas de Malafaia e seus candidatos, encontrando razões que diferenciam o seguir religioso dentro do espaço geográfico da igreja e o seguir político de um povo que o pastor pretende em tudo influenciar, ainda que na esfera pública de um mundo secularizado a história se mostre outra, como se poderá ver.

\section{0: Paradigma para uma geografia do} voto

Não são raras, em tempos de eleições, as muitas visitações de candidatos a templos religiosos, no intuito de angariar a simpatia e o voto de grandes contingentes populacionais que frequentam tais espaços. No entanto, por mais que essa prática tenha se repetido inúmeras vezes na vida de vários candidatos, como também foi o caso de Dilma Rousseff e José Serra em 2010, os números mostram que o fator religião não tem toda a relevância que muitos defendem, 
ainda que, midiática e qualitativamente, uma visitação dessa natureza possa fazer muita diferença para uma candidatura.

Ao fazer uma rápida visita às reportagens sobre os candidatos no período pré-eleitoral em 2010, é possível deparar-se com uma série de acontecimentos que, em si, deveriam ser justificados por uma grande relevância da variável religião na eleição. Olhando por exemplo para a agenda dos candidatos, é possível perceber uma semelhança nas visitações e pedidos de bênçãos e apoio aos líderes das mais variadas denominações religiosas da nação, sobretudo do movimento evangélico, que, como já foi mostrado, à luz do Censo 2010, é o segmento religioso que mais cresce no país.

Acontece, no entanto, que a prática de tocar em temas religiosos, como é sabido, não é nova em tempos de eleições. Tendo como base uma reportagem de outubro de 2010 da Revista Época 2, é possível fazer uma visitação aos acontecimentos que antecederam eleições anteriores, encontrando assim exemplos de eleições permeadas pelo fator religião, como foi o caso da derrota de Fernando Henrique Cardoso para Jânio Quadros, em 1985, simplesmente porque em debate televisivo pela prefeitura de São Paulo aquele candidato não teria sido claro ao responder se acreditava em Deus. Assim também aconteceu com a postura de lideranças evangélicas que recomendaram o voto em Fernando Collor de Mello, já que, no discurso de tais líderes da época, o projeto do PT de Lula, além de ter cores socialistas, tinha ligação direta com a igreja católica. $^{3}$

A pauta religiosa de 2010, para além de "cores socialistas" e "crença em Deus", entretanto, versava sobre a postura dos candidatos frente a temas como aborto, eutanásia e casamento entre pessoas do mesmo sexo. Nesta direção, Dilma Rousseff parecia estar em desvantagem, uma vez que o governo de seu padrinho político visava implementar o que ficou conhecido como PNDH3 (Plano Nacional de Direitos Humanos), onde a descriminalização do aborto, a união civil de homossexuais e outros pleitos de algumas das minorias do país estavam contemplados. Focando na possível desvantagem da candidata, a reportagem da Revista Época, das Organizações Globo, afirmava que

A polêmica religiosa deu à oposição a oportunidade de tomar a iniciativa na campanha política, pôs Dilma e o PT na defensiva e redefiniu o segundo turno. Na sextafeira, quando foram ao ar as primeiras peças de propaganda eleitoral gratuita, o uso da carta religiosa ficou claro. Dilma agradeceu a Deus, se declarou "a favor da 
vida" e disse que é vítima de uma "campanha de calúnias", como ocorreu com Lula no passado. $\mathrm{O}$ programa mencionou a existência de "uma corrente do mal na internet" contra ela. Serra se apresentou como temente a Deus, defensor da vida e inimigo do aborto (apesar de seu partido, o PSDB, ter apresentado nos anos 90 um projeto de legalização do aborto no Senado). Pôs seis grávidas em cena e prometeu programas federais para "cuidar dos bebês mesmo antes que eles nasçam. (REVISTA ÉPOCA, 2010)

Por mais que os números que serão à frente apresentados refutem a relevância estatística do fator religião, é inegável o peso qualitativo de uma reportagem onde as declarações de um especialista e as de um fiel evangélico servem como base para inferências que os números ulteriormente não confirmariam. Retirando $\mathrm{o}$ foco de temas que sempre foram caros em um período eleitoral, a revista das Organizações Globo continua sua reportagem dizendo que a elevação do padrão de vida dos pobres e a superação das necessidades elementares de sobrevivência podem ter começado a abrir espaço para aquilo que, em democracias mais maduras, é conhecido como "agenda de valores". Ela reúne temas como fé, aborto, eutanásia, ensino religioso, casamento entre homossexuais ou pesquisas com manipulação genética. 'Ninguém mais vai se eleger para um cargo executivo facilmente com um programa que prevê a legalização do aborto', afirma Ary Oro, estudioso de religião e política da Universidade Federal do Rio Grande do Sul. 'É impossível ignorar a força numérica, demográfica e eleitoral da religião'. (Ibidem, 2010)

Ainda sem acesso às informações em números sobre o voto religioso, que seriam trazidos no final daquele mês de outubro (a reportagem da revista é do início do mesmo mês), Época explorou a possível 
"força numérica, demográfica e eleitoral da religião", focando possibilidades de qualificar o discurso de Ary Oro, já que, quantitativamente, como ser verá aqui, ainda não era possível referendá-lo. Nesta direção, a revista estampou declarações que, ainda sem uma confirmação em pesquisa, teriam tudo para demonstrar grande força, como se pode ver em depoimentos explorados na época.

A onda emocional que Dilma está enfrentando pode ser avaliada pelo depoimento do evangélico carioca Otacílio Galdino Soares, de 34 anos. Ele diz que planejava votar em Dilma no primeiro turno - "por causa de Lula" -, mas mudou de ideia. "Ouvi na igreja que ela é a favor do casamento gay, isso é uma coisa abominável aos olhos de Deus", diz Galdino. Frequentador da igreja Casa da Bênção e morador de Jacarepaguá, Zona Oeste do Rio de Janeiro, ele está desempregado. Diz-se satisfeito com o governo, mas começou a ter informações ruins sobre
Dilma com o pastor e outros fiéis. "A notícia corre, o boca a boca é forte", afirma. 'Ouvi que ela disse que nem Jesus Cristo tirava essa eleição dela. Como alguém pode achar que é maior do que Deus?'. Dilma nega ter dito essa frase infeliz, mas o boato, alimentado pelo jogo sujo da política, prevaleceu. (Ibidem, 2010)

Para além de sua revista de notícias semanais, também foi possível encontrar a pauta religiosa no principal telejornal das Organizações Globo. $\mathrm{Na}$ tradicional entrevista pré-eleitoral com os candidatos, foi possível ver a defesa de Serra quanto a temas que poderiam ferir a religiosidade de muitos. Buscando reportagem que relembra a entrevista do candidato, é possível ver que Questionado pelos apresentadores sobre as razões que o levaram a alimentar a polêmica sobre o aborto, inclusive no horário eleitoral obrigatório, o tucano respondeu: 'Não fomos nós que levantamos, nem nós exploramos'. Pouco depois, afirmou: 'Quem 
introduziu

esse

ingrediente foi o PT, e foi

a Dilma'.

$\mathrm{O}$

presidenciável afirmou

que a discussão sobre o tema só surgiu por conta do Plano Nacional de

Direitos Humanos, do governo Luiz Inácio Lula da Silva, e de declarações de Dilma a favor da descriminalização do aborto, atenuadas às vésperas das eleições. 'Nunca explorei isso do ponto de vista que ela estaria errada por ser a favor'. 4

O que acontece é que ela afirmou uma coisa e depois afirmou o oposto. Nem reconhece que disse o oposto, e, numa campanha, esses temas acabam sendo postos pela própria população. Nunca me passou pela cabeça transformar isso num centro de campanha', disse Serra. 'A candidata passou a frequentar igrejas, coisa que ela não fazia. A base disso está no fato de que uma hora ela diz uma coisa e em outra hora ela diz o oposto. 5

Tendo ou não sido o responsável pela introdução no debate eleitoral de temas que afetam diretamente à religiosidade popular, o candidato José Serra não dispensou aquilo que se acreditava ser uma busca por um significativo montante de votos. Tanto que em seu programa político começou a ser veiculada a imagem de um dos mais conhecidos líderes evangélicos do Brasil, o pastor Silas Malafaia, da Assembleia de Deus Vitória em Cristo. Em fala que dispensava a identificação partidária, o líder religioso apoiador de Serra dizia: "para ser presidente, tem que estar acima dos partidos, e aí, querido, para isso, nós só temos uma pessoa: Serra". (Ibidem, 2010)

Embora naquele ano a candidata evangélica Marina Silva devesse pela lógica ser a opção de Malafaia e seus milhões de seguidores, o pastor afirmou que " $a$ irmã Marina ficou em cima do muro quanto à proposta de plebiscito para a liberação do aborto e da maconha", o que confirma a tese de Souza (2014) quando este defende que "a pauta apresentada não tem nada de especificamente evangélica, mas é apenas uma pauta conservadora, que não representa o grosso da população evangélica" Foi interessante notar, no entanto, que as imagens do pastor Silas Malafaia começaram a ser veiculadas na mesma 
semana em que um vídeo mostrou José Serra defendendo a união civil de homossexuais e a adoção de crianças por casais gays durante uma sabatina do jornal Folha de São Paulo e do UOL (2010) ${ }^{6}$, e também na mesma semana em que exalunas da mulher de José Serra, Mônica Serra, disseram que ela admitiu ter feito um aborto quando estava exilada com o marido no Chile.

Assim, o apoio evangélico à candidatura de José Serra pareceu ter outras motivações, que só uma pesquisa qualitativa específica poderia mostrar, uma vez que temas como união civil de homossexuais, adoção de crianças por casais gays e aborto frequentemente são bastante criticados por pastores e líderes religiosos em geral, e em particular por Silas Malafaia em seu programa de televisão, sendo que o tema aborto foi o que, segundo o próprio pastor, o fez deixar de apoiar a candidata Marina Silva e declarar seu voto ao candidato José Serra. É importante também lembrar que, para além de Malafaia, o candidato do PSDB também buscou votos "religiosos" com o apóstolo Valdemiro Santiago, da Igreja Mundial do Poder de Deus, e com o pastor José Wellington Bezerra, presidente da Convenção Geral das Assembleias de Deus do Brasil. ${ }^{7}$

Se o fator religião afetou diretamente a campanha do tucano José Serra, o mesmo pode também ser dito da concorrente Dilma Rousseff. Cumprindo a mesma agenda de Serra, segundo informações do jornal $O$ Estado de São Paulo, a candidata petista buscou alianças com a Assembleia de Deus e participou de reuniões com os líderes das principais denominações religiosas do país. ${ }^{8}$

Cumprindo agenda muito parecida com a de Serra, Dilma participou, ao lado de seu antecessor, o ex-presidente Lula, de concentrações de fé da Igreja Mundial do Poder de Deus, do apóstolo Valdemiro Santiago, dando, segundo o Diário do Grande ABC, e nas palavras de Fábio Bmed, “caráter político à atividade religiosa", com pastores das igrejas dando ampla divulgação das duas presenças ilustres nos cultos e com a oportunidade de o ex-presidente apresentar sua candidata ${ }^{9}$.

Em visitas justificadoras de uma geografia do voto, muitos constrangimentos, já que se tratava de espaços aos quais nem Dilma e nem Serra pertenciam, o que fez surgir pistas para que tal barulho seja repetido a cada eleição, algo que se justifica, por exemplo, na cifra de fieis apresentadas pelos líderes da Assembleia de Deus, maior denominação evangélica do país, que afirmam ter entre 20 e 23 milhões de seguidores, o que se mostra uma possibilidade eleitoral que não seria ser ignorada por qualquer um dos candidatos. ${ }^{10}$

Se Serra conseguiu o apoio explícito de alguns dos mais influentes líderes evangélicos da nação, o mesmo pode ser dito de Dilma, já que, numa 
costura de apoio que já vinha desde o governo Lula, a Convenção Geral das Assembleias de Deus, liderada pelo bispo Manoel Ferreira, também foi procurada por Dilma e a ela ofereceu seu apoio, sendo alvo de protestos, não apenas entre os seus pares, mas também de outras denominações, como foi o caso dos evangélicos batistas. ${ }^{11}$

$\mathrm{Na}$ tentativa de defender Dilma dos ataques a ela feitos, sobretudo por conta do PNDH3, que trazia apoio a temas como aborto e casamento entre homossexuais, o bispo Ferreira afirmou que Dilma não seria responsável por isso, mas que essa pauta caberia exclusivamente ao Congresso Nacional, não sendo objeto de iniciativa do Executivo, para o qual Dilma concorria. ${ }^{13}$

$\mathrm{O}$ interessante em todo o debate sobre a presença religiosa na eleição de 2010 é que os números que viriam em pesquisa do Ibope no final daquele mês de tantas visitas a templos religiosos e tantas polêmicas em torno do PNDH3 não mostrariam a tal relevância do fator religião, relevância tão apregoada por líderes religiosos e até por um especialista no tema, Ary Oro, pesquisador de religião e política da Universidade Federal do Rio Grande do Sul, já aqui apresentado.

\section{Dados para um discurso que não se justifica}

Pensando em uma geografia do voto e lançando mão da pesquisa aqui anunciada, é possível ver pela tabela 1 que, quando perguntados se o estabelecimento religioso que frequentam ofereceu orientação para que não votassem em um específico candidato, mais de $90 \%$ dos eleitores religiosos disseram que não receberam tal orientação. Assim, ainda que um pequeno contingente tenha recebido de seus líderes uma indicação sobre quem evitar na eleição 2010, tal orientação dificilmente teria peso para mudar um resultado eleitoral.

Focando apenas os candidatos que interessam a essa parte da presente pesquisa, do já minúsculo contingente de menos de $10 \%$ dos que receberam tal orientação, a diferença entre Dilma e Serra neste quesito não passa de 1 ponto percentual. Se $6 \%$ do já pequeno percentual foi indicado a evitar o voto em Dilma, outros insignificantes $2 \%$ foram instados a evitar o voto em Serra, como mostra a tabela que segue.

Os já insignificantes números da orientação religiosa são somados aos ainda menos significativos gestos de aceitação, uma vez que, como mostra a tabela 2 , apenas $1 \%$ dos que receberem tal indicação acatou o pedido dos líderes religiosos que são por eles seguidos. À luz de tais números, portanto, é possível inferir que religião, ainda que pareça, não tem qualquer 
peso estatístico, enquanto variável explicativa em um pleito eleitoral, ainda que qualitativamente tal constatação possa ser problematizada.

No nível da pesquisa qualitativa, então, talvez se possa encontrar elementos a justificarem a presença da pauta religiosa na agenda dos candidatos, uma vez que, em números, não se pode mensurar o efeito da presença de cada candidato nos redutos e programas religiosos.
Como única curiosidade a ser trazida por conta da questão agora analisada, fica a lembrança de que, mesmo sem qualquer relevância estatística para mudar o pleito que estava em questão em 2010, apenas os nomes de José Serra e Dilma Rousseff foram lembrados como candidatos que se deveria evitar, ficando inclusive o PT, bem como qualquer outro partido, sem qualquer menção nesta direção, como se poderá ver pelas tabelas que seguem. 


\begin{tabular}{|c|c|c|c|c|c|c|c|c|c|c|c|}
\hline \multirow[b]{2}{*}{ RESPOSTA } & & \multirow[b]{2}{*}{ TOTAL } & \multicolumn{4}{|c|}{$\begin{array}{l}\text { RENDA FAMILIAR (EM } \\
\text { SALÁRIOS MÍNIMOS) }\end{array}$} & \multicolumn{5}{|c|}{ RAÇA } \\
\hline & & & $\begin{array}{l}\text { MAIS } \\
\text { DE 5 }\end{array}$ & 2 A 5 & $1 \mathrm{~A} 2$ & $\begin{array}{c}\text { ATÉ } \\
1\end{array}$ & BRANCA & PRETA & PARDA & AMARELA & INDÍGENA \\
\hline \multirow{2}{*}{ BASE } & & 2.583 & 349 & 837 & 867 & 418 & 1.148 & 355 & 989 & 49 & 42 \\
\hline & $\% \mathrm{H}$ & $100 \%$ & $14 \%$ & $34 \%$ & $35 \%$ & $17 \%$ & $44 \%$ & $14 \%$ & $38 \%$ & $2 \%$ & $2 \%$ \\
\hline \multirow{3}{*}{ Dilma } & ABS & 39 & 6 & 12 & 14 & 6 & 15 & 8 & 14 & 1 & 1 \\
\hline & $\% \mathrm{~V}$ & $2 \%$ & $2 \%$ & $1 \%$ & $2 \%$ & $1 \%$ & $1 \%$ & $2 \%$ & $1 \%$ & $2 \%$ & $2 \%$ \\
\hline & $\% \mathrm{H}$ & $100 \%$ & $16 \%$ & $32 \%$ & $37 \%$ & $16 \%$ & $38 \%$ & $21 \%$ & $36 \%$ & $3 \%$ & $3 \%$ \\
\hline \multirow{3}{*}{ José Serra } & ABS & 12 & 1 & 5 & 5 & 1 & 7 & 1 & 3 & 0 & 1 \\
\hline & $\% \mathrm{~V}$ & $0 \%$ & $0 \%$ & $1 \%$ & $1 \%$ & $0 \%$ & $1 \%$ & $0 \%$ & $0 \%$ & $0 \%$ & $2 \%$ \\
\hline & $\% \mathrm{H}$ & $100 \%$ & $8 \%$ & $42 \%$ & $42 \%$ & $8 \%$ & $58 \%$ & $8 \%$ & $25 \%$ & $0 \%$ & $8 \%$ \\
\hline \multirow{3}{*}{ Levy Fidelix } & ABS & 1 & 0 & 0 & 1 & 0 & 1 & 0 & 0 & 0 & 0 \\
\hline & $\% \mathrm{~V}$ & $0 \%$ & $0 \%$ & $0 \%$ & $0 \%$ & $0 \%$ & $0 \%$ & $0 \%$ & $0 \%$ & $0 \%$ & $0 \%$ \\
\hline & $\% \mathrm{H}$ & $100 \%$ & $0 \%$ & $0 \%$ & $100 \%$ & $0 \%$ & $100 \%$ & $0 \%$ & $0 \%$ & $0 \%$ & $0 \%$ \\
\hline \multirow{3}{*}{ Marina Silva } & ABS & 6 & 1 & 2 & 2 & 1 & 2 & 0 & 4 & 0 & 0 \\
\hline & $\% \mathrm{~V}$ & $0 \%$ & $0 \%$ & $0 \%$ & $0 \%$ & $0 \%$ & $0 \%$ & $0 \%$ & $0 \%$ & $0 \%$ & $0 \%$ \\
\hline & $\% \mathrm{H}$ & $100 \%$ & $17 \%$ & $33 \%$ & $33 \%$ & $17 \%$ & $33 \%$ & $0 \%$ & $67 \%$ & $0 \%$ & $0 \%$ \\
\hline \multirow{3}{*}{$\begin{array}{l}\text { Rui Costa } \\
\text { Pimenta }\end{array}$} & ABS & 4 & 0 & 0 & 1 & 3 & 2 & 1 & 1 & 0 & 0 \\
\hline & $\% \mathrm{~V}$ & $0 \%$ & $0 \%$ & $0 \%$ & $0 \%$ & $1 \%$ & $0 \%$ & $0 \%$ & $0 \%$ & $0 \%$ & $0 \%$ \\
\hline & $\% \mathrm{H}$ & $100 \%$ & $0 \%$ & $0 \%$ & $25 \%$ & $75 \%$ & $50 \%$ & $25 \%$ & $25 \%$ & $0 \%$ & $0 \%$ \\
\hline \multirow{3}{*}{ Zé Maria } & ABS & 1 & 0 & 0 & 1 & 0 & 1 & 0 & 0 & 0 & 0 \\
\hline & $\% \mathrm{~V}$ & $0 \%$ & $0 \%$ & $0 \%$ & $0 \%$ & $0 \%$ & $0 \%$ & $0 \%$ & $0 \%$ & $0 \%$ & $0 \%$ \\
\hline & $\% \mathrm{H}$ & $100 \%$ & $0 \%$ & $0 \%$ & $100 \%$ & $0 \%$ & $100 \%$ & $0 \%$ & $0 \%$ & $0 \%$ & $0 \%$ \\
\hline \multirow{3}{*}{ PT (Esp.) } & ABS & 1 & 0 & 1 & 0 & 0 & 0 & 0 & 1 & 0 & 0 \\
\hline & $\% \mathrm{~V}$ & $0 \%$ & $0 \%$ & $0 \%$ & $0 \%$ & $0 \%$ & $0 \%$ & $0 \%$ & $0 \%$ & $0 \%$ & $0 \%$ \\
\hline & $\% \mathrm{H}$ & $100 \%$ & $0 \%$ & $100 \%$ & $0 \%$ & $0 \%$ & $0 \%$ & $0 \%$ & $100 \%$ & $0 \%$ & $0 \%$ \\
\hline \multirow{3}{*}{$\begin{array}{l}\text { Outro partido } \\
\text { (Esp.) }\end{array}$} & ABS & 12 & 3 & 4 & 3 & 0 & 5 & 3 & 4 & 0 & 0 \\
\hline & $\% \mathrm{~V}$ & $0 \%$ & $1 \%$ & $0 \%$ & $0 \%$ & $0 \%$ & $0 \%$ & $1 \%$ & $0 \%$ & $0 \%$ & $0 \%$ \\
\hline & $\% \mathrm{H}$ & $100 \%$ & $30 \%$ & $40 \%$ & $30 \%$ & $0 \%$ & $42 \%$ & $25 \%$ & $33 \%$ & $0 \%$ & $0 \%$ \\
\hline \multirow{3}{*}{ Não recebeu } & ABS & 2446 & 329 & 798 & 823 & 391 & 1085 & 329 & 947 & 46 & 39 \\
\hline & $\% \mathrm{~V}$ & $95 \%$ & $94 \%$ & $95 \%$ & $95 \%$ & $94 \%$ & $95 \%$ & $93 \%$ & $96 \%$ & $94 \%$ & $93 \%$ \\
\hline & $\% \mathrm{H}$ & $100 \%$ & $14 \%$ & $34 \%$ & $35 \%$ & $17 \%$ & $44 \%$ & $13 \%$ & $39 \%$ & $2 \%$ & $2 \%$ \\
\hline \multirow{3}{*}{$\begin{array}{l}\text { Não } \\
\text { respondeu }\end{array}$} & ABS & 61 & 9 & 15 & 17 & 16 & 30 & 13 & 15 & 2 & 1 \\
\hline & $\% \mathrm{~V}$ & $2 \%$ & $3 \%$ & $2 \%$ & $2 \%$ & $4 \%$ & $3 \%$ & $4 \%$ & $2 \%$ & $4 \%$ & $2 \%$ \\
\hline & $\% \mathrm{H}$ & $100 \%$ & $16 \%$ & $26 \%$ & $30 \%$ & $28 \%$ & $49 \%$ & $21 \%$ & $25 \%$ & $3 \%$ & $2 \%$ \\
\hline
\end{tabular}

Fonte: IBOPE inteligência, 2010 


\begin{tabular}{|c|c|c|c|c|c|c|c|c|c|c|c|}
\hline \multirow{2}{*}{\multicolumn{2}{|c|}{ RESPOSTA }} & \multirow{3}{*}{$\begin{array}{c}\text { TOTAL } \\
2.583 \\
\end{array}$} & \multicolumn{4}{|c|}{$\begin{array}{l}\text { RENDA FAMILIAR (EM } \\
\text { SALÁRIOS MÍNIMOS) }\end{array}$} & \multicolumn{5}{|c|}{ RAÇA } \\
\hline & & & $\begin{array}{l}\text { MAIS } \\
\text { DE 5 } \\
\end{array}$ & 2 A 5 & $1 \mathrm{~A} 2$ & ATÉ 1 & BRANCA & PRETA & PARDA & $\begin{array}{c}\text { AMAREL } \\
\text { A } \\
\end{array}$ & INDÍGENA \\
\hline \multirow{2}{*}{ BASE } & & & 349 & 837 & 867 & 418 & 1.148 & 355 & 989 & 49 & 42 \\
\hline & $\% \mathrm{H}$ & $100 \%$ & $14 \%$ & $34 \%$ & $35 \%$ & $17 \%$ & $44 \%$ & $14 \%$ & $38 \%$ & $2 \%$ & $2 \%$ \\
\hline \multirow{3}{*}{$\begin{array}{c}\text { Acatou } \\
\text { orientação }\end{array}$} & ABS & 25 & 1 & 9 & 8 & 7 & 7 & 4 & 11 & 1 & 2 \\
\hline & $\% \mathrm{~V}$ & $1 \%$ & $0 \%$ & $1 \%$ & $1 \%$ & $2 \%$ & $1 \%$ & $1 \%$ & $1 \%$ & $2 \%$ & $5 \%$ \\
\hline & $\% \mathrm{H}$ & $100 \%$ & $4 \%$ & $36 \%$ & $32 \%$ & $28 \%$ & $28 \%$ & $16 \%$ & $44 \%$ & $4 \%$ & $8 \%$ \\
\hline \multirow{3}{*}{$\begin{array}{l}\text { Não acatou } \\
\text { orientação }\end{array}$} & ABS & 36 & 7 & 9 & 14 & 4 & 16 & 8 & 12 & 0 & 0 \\
\hline & $\% \mathrm{~V}$ & $1 \%$ & $2 \%$ & $1 \%$ & $2 \%$ & $1 \%$ & $1 \%$ & $2 \%$ & $1 \%$ & $0 \%$ & $0 \%$ \\
\hline & $\% \mathrm{H}$ & $100 \%$ & $21 \%$ & $26 \%$ & $41 \%$ & $12 \%$ & $44 \%$ & $22 \%$ & $33 \%$ & $0 \%$ & $0 \%$ \\
\hline \multirow{3}{*}{$\begin{array}{c}\text { Não } \\
\text { recebeu } \\
\text { orientação/ } \\
\text { não } \\
\text { respondeu }\end{array}$} & ABS & 2.522 & 341 & 819 & 845 & 407 & 1.125 & 343 & 966 & 48 & 40 \\
\hline & $\% \mathrm{~V}$ & $98 \%$ & $98 \%$ & $98 \%$ & $97 \%$ & $97 \%$ & $98 \%$ & $97 \%$ & $98 \%$ & $98 \%$ & $95 \%$ \\
\hline & $\% \mathrm{H}$ & $100 \%$ & $14 \%$ & $34 \%$ & $35 \%$ & $17 \%$ & $45 \%$ & $14 \%$ & $38 \%$ & $2 \%$ & $2 \%$ \\
\hline
\end{tabular}

Se a indicação negativa não teve relevância estatística no pleito de 2010, a orientação positiva também não conseguiu se mostrar com força para fazer da religião uma variável explicativa de peso. Seguindo a lógica negativa, a indicação de um determinado candidato também não conseguiu alcançar um percentual de $10 \%$ dos eleitores pesquisados, já que novamente mais de $90 \%$ afirmam não terem sidos instados a votar num ou noutro candidato ou partido, como mostram as tabelas 3 e 4 .

$$
\text { É claro que uma pesquisa }
$$
qualitativa poderá encontrar elementos interessantes e até intrigantes acerca da temática agora proposta. No entanto, apesar de uma pesquisa que leve em conta um específico estudo de caso ou de um grupo focal (uma determinada denominação religiosa, por exemplo) poder trazer elementos antropológicos dignos de uma boa análise, no nível da inferência para o geral da população isso não teria qualquer relevância, enquanto elemento para alterar um resultado eleitoral, visto que a não indicação de um candidato pela liderança religiosa chegou aos robustos $97 \%$, como é possível ver pelos números da tabela 4 . 
Tabela 3 - O(a) sr(a) recebeu alguma orientação na igreja, templo ou estabelecimento religioso que frequenta para que votasse em algum candidato a Presidente ou partido? (Caso sim) Em qual destes candidatos?

\begin{tabular}{|c|c|c|c|c|c|c|c|c|c|c|c|}
\hline \multirow{2}{*}{\multicolumn{2}{|c|}{ RESPOSTA }} & \multirow{3}{*}{$\frac{\text { TOTAL }}{2.583}$} & \multicolumn{4}{|c|}{$\begin{array}{l}\text { RENDA FAMILIAR (EM SALÁRIOS } \\
\text { MÍNIMOS) }\end{array}$} & \multicolumn{5}{|c|}{ RAÇA } \\
\hline & & & $\begin{array}{l}\text { MAIS } \\
\text { DE } 5 \\
\end{array}$ & 2 A 5 & $1 \mathrm{~A} 2$ & ATÉ 1 & BRANCA & PRETA & PARDA & AMARELA & $\begin{array}{l}\text { INDÍG } \\
\text { ENA }\end{array}$ \\
\hline \multirow{2}{*}{ BASE } & & & 349 & 837 & 867 & 418 & 1.148 & 355 & 989 & 49 & 42 \\
\hline & $\% \mathrm{H}$ & $100 \%$ & $14 \%$ & $34 \%$ & $35 \%$ & $17 \%$ & $44 \%$ & $14 \%$ & $38 \%$ & $2 \%$ & $2 \%$ \\
\hline \multirow{3}{*}{ Dilma } & ABS & 17 & 5 & 5 & 5 & 1 & 6 & 3 & 5 & 2 & 1 \\
\hline & $\% \mathrm{~V}$ & $1 \%$ & $1 \%$ & $1 \%$ & $1 \%$ & $0 \%$ & $1 \%$ & $1 \%$ & $1 \%$ & $4 \%$ & $2 \%$ \\
\hline & $\% \mathrm{H}$ & $100 \%$ & $31 \%$ & $31 \%$ & $31 \%$ & $6 \%$ & $35 \%$ & $18 \%$ & $29 \%$ & $12 \%$ & $6 \%$ \\
\hline \multirow{3}{*}{ Eymael } & ABS & 9 & 0 & 0 & 7 & 2 & 5 & 1 & 3 & 0 & 0 \\
\hline & $\% \mathrm{~V}$ & $0 \%$ & $0 \%$ & $0 \%$ & $1 \%$ & $0 \%$ & $0 \%$ & $0 \%$ & $0 \%$ & $0 \%$ & $0 \%$ \\
\hline & $\% \mathrm{H}$ & $100 \%$ & $0 \%$ & $0 \%$ & $78 \%$ & $22 \%$ & $56 \%$ & $11 \%$ & $33 \%$ & $0 \%$ & $0 \%$ \\
\hline \multirow{3}{*}{ José Serra } & ABS & 9 & 0 & 4 & 3 & 2 & 3 & 1 & 5 & 0 & 0 \\
\hline & $\% \mathrm{~V}$ & $0 \%$ & $0 \%$ & $0 \%$ & $0 \%$ & $0 \%$ & $0 \%$ & $0 \%$ & $1 \%$ & $0 \%$ & $0 \%$ \\
\hline & $\% \mathrm{H}$ & $100 \%$ & $0 \%$ & $44 \%$ & $33 \%$ & $22 \%$ & $33 \%$ & $11 \%$ & $56 \%$ & $0 \%$ & $0 \%$ \\
\hline \multirow{3}{*}{$\begin{array}{l}\text { Marina } \\
\text { Silva }\end{array}$} & $A B S$ & 18 & 1 & 6 & 6 & 5 & 4 & 3 & 8 & 0 & 3 \\
\hline & $\% \mathrm{~V}$ & $1 \%$ & $0 \%$ & $1 \%$ & $1 \%$ & $1 \%$ & $0 \%$ & $1 \%$ & $1 \%$ & $0 \%$ & $7 \%$ \\
\hline & $\% \mathrm{H}$ & $100 \%$ & $6 \%$ & $33 \%$ & $33 \%$ & $28 \%$ & $22 \%$ & $17 \%$ & $44 \%$ & $0 \%$ & $17 \%$ \\
\hline \multirow{3}{*}{$\begin{array}{l}\text { PSDB } \\
\text { (Esp.) }\end{array}$} & ABS & 1 & 0 & 1 & 0 & 0 & 1 & 0 & 0 & 0 & 0 \\
\hline & $\% \mathrm{~V}$ & $0 \%$ & $0 \%$ & $0 \%$ & $0 \%$ & $0 \%$ & $0 \%$ & $0 \%$ & $0 \%$ & $0 \%$ & $0 \%$ \\
\hline & $\% \mathrm{H}$ & $100 \%$ & $0 \%$ & $100 \%$ & $0 \%$ & $0 \%$ & $100 \%$ & $0 \%$ & $0 \%$ & $0 \%$ & $0 \%$ \\
\hline \multirow{3}{*}{$\begin{array}{l}\text { Outro } \\
\text { partido } \\
\text { (Esp.) }\end{array}$} & ABS & 10 & 0 & 5 & 2 & 2 & 3 & 1 & 6 & 0 & 0 \\
\hline & $\% \mathrm{~V}$ & $0 \%$ & $0 \%$ & $1 \%$ & $0 \%$ & $0 \%$ & $0 \%$ & $0 \%$ & $1 \%$ & $0 \%$ & $0 \%$ \\
\hline & $\% \mathrm{H}$ & $100 \%$ & $0 \%$ & $56 \%$ & $22 \%$ & $22 \%$ & $30 \%$ & $10 \%$ & $60 \%$ & $0 \%$ & $0 \%$ \\
\hline \multirow{3}{*}{$\begin{array}{l}\text { Não } \\
\text { recebeu }\end{array}$} & ABS & 2429 & 333 & 791 & 815 & 382 & 1080 & 329 & 938 & 45 & 37 \\
\hline & $\% \mathrm{~V}$ & $94 \%$ & $95 \%$ & $95 \%$ & $94 \%$ & $91 \%$ & $94 \%$ & $93 \%$ & $95 \%$ & $92 \%$ & $88 \%$ \\
\hline & $\% \mathrm{H}$ & $100 \%$ & $14 \%$ & $34 \%$ & $35 \%$ & $16 \%$ & $44 \%$ & $14 \%$ & $39 \%$ & $2 \%$ & $2 \%$ \\
\hline \multirow{3}{*}{$\begin{array}{l}\text { Não } \\
\text { respondeu }\end{array}$} & ABS & 90 & 10 & 25 & 29 & 24 & 46 & 17 & 24 & 2 & 1 \\
\hline & $\% \mathrm{~V}$ & $3 \%$ & $3 \%$ & $3 \%$ & $3 \%$ & $6 \%$ & $4 \%$ & $5 \%$ & $2 \%$ & $4 \%$ & $2 \%$ \\
\hline & $\% \mathrm{H}$ & $100 \%$ & $11 \%$ & $28 \%$ & $33 \%$ & $27 \%$ & $51 \%$ & $19 \%$ & $27 \%$ & $2 \%$ & $1 \%$ \\
\hline
\end{tabular}

Fonte: IBOPE inteligência,2010 
Tabela 4 - E o(a) sr(a) acatou ou não a orientação da sua igreja, templo ou estabelecimento religioso?

\begin{tabular}{|c|c|c|c|c|c|c|c|c|c|c|c|}
\hline \multirow{2}{*}{\multicolumn{2}{|c|}{ RESPOSTA }} & \multirow[b]{2}{*}{ TOTAL } & \multicolumn{4}{|c|}{$\begin{array}{l}\text { RENDA FAMILIAR (EM } \\
\text { SALÁRIOS MÍNIMOS) }\end{array}$} & \multicolumn{5}{|c|}{ RAÇA } \\
\hline & & & $\begin{array}{l}\text { MAIS } \\
\text { DE } 5\end{array}$ & 2 A 5 & $1 \mathrm{~A} 2$ & ATÉ 1 & BRANCA & PRETA & PARDA & AMARELA & $\begin{array}{c}\text { INDÍGEN } \\
\mathrm{A}\end{array}$ \\
\hline \multirow{2}{*}{ BASE } & & 2.583 & 349 & 837 & 867 & 418 & 1.148 & 355 & 989 & 49 & 42 \\
\hline & $\% \mathrm{H}$ & $100 \%$ & $14 \%$ & $34 \%$ & $35 \%$ & $17 \%$ & $44 \%$ & $14 \%$ & $38 \%$ & $2 \%$ & $2 \%$ \\
\hline \multirow{3}{*}{$\begin{array}{l}\text { Acatou } \\
\text { orientaç } \\
\text { ão }\end{array}$} & ABS & 30 & 0 & 12 & 10 & 8 & 9 & 4 & 13 & 1 & 3 \\
\hline & $\% \mathrm{~V}$ & $1 \%$ & $0 \%$ & $1 \%$ & $1 \%$ & $2 \%$ & $1 \%$ & $1 \%$ & $1 \%$ & $2 \%$ & $7 \%$ \\
\hline & $\% \mathrm{H}$ & $100 \%$ & $0 \%$ & $40 \%$ & $33 \%$ & $27 \%$ & $30 \%$ & $13 \%$ & $43 \%$ & $3 \%$ & $10 \%$ \\
\hline \multirow{3}{*}{$\begin{array}{l}\text { Não } \\
\text { acatou } \\
\text { orientaç } \\
\text { ão }\end{array}$} & ABS & 27 & 5 & 7 & 9 & 4 & 10 & 3 & 12 & 1 & 1 \\
\hline & $\% \mathrm{~V}$ & $1 \%$ & $1 \%$ & $1 \%$ & $1 \%$ & $1 \%$ & $1 \%$ & $1 \%$ & $1 \%$ & $2 \%$ & $2 \%$ \\
\hline & $\% \mathrm{H}$ & $100 \%$ & $20 \%$ & $28 \%$ & $36 \%$ & $16 \%$ & $37 \%$ & $11 \%$ & $44 \%$ & $4 \%$ & $4 \%$ \\
\hline \multirow{3}{*}{$\begin{array}{l}\text { Não } \\
\text { recebeu } \\
\text { orientaç } \\
\text { ão/não } \\
\text { respond } \\
\text { eu }\end{array}$} & ABS & 2.526 & 344 & 818 & 848 & 406 & 1.129 & 348 & 964 & 47 & 38 \\
\hline & $\% \mathrm{~V}$ & $98 \%$ & $99 \%$ & $98 \%$ & $98 \%$ & $97 \%$ & $98 \%$ & $98 \%$ & $97 \%$ & $96 \%$ & $90 \%$ \\
\hline & $\% \mathrm{H}$ & $100 \%$ & $14 \%$ & $34 \%$ & $35 \%$ & $17 \%$ & $45 \%$ & $14 \%$ & $38 \%$ & $2 \%$ & $2 \%$ \\
\hline
\end{tabular}

Assim, como se pode ver pelos dados apresentados, fica a indicação de que o voto em Dilma ou em Serra - levando-se em conta as principais variáveis explicativas para o voto - poderá ser analisado pela renda familiar, pela cor/raça e por outras variáveis como região, participação ou não em algum programa social, idade, sexo, percepção de si no estado de coisas vigente e preferência partidária.

No entanto, como ficou mostrado, a religiosidade dos eleitores, embora abra pauta para uma investigação de cunho

http://www.e-publicacoes.uerj.br/index.php/espacoecultura/ qualitativo, não se consegue inserir no conjunto de variáveis que influenciam ou mudam o rumo de uma eleição, sendo apenas "moeda de troca" de líderes que pregam ousadamente que detém um imenso contingente de eleitores em suas mãos, mas que, ao fim e ao cabo, não influenciam nem $2 \%$ do contingente dos eleitores que lhes seguem em espaços sagrados, o que referenda a tese de Campos, para quem tudo não passa de um grande empreendimento religioso, apenas afeito a uma cruel lógica de mercado, mas que não atinge a dimensão da participação política. (CAMPOS, 1997) da pa9-115, JAN./JUN. DE 2015 
Portanto, parece fazer muito sentido a ideia de que "a igreja é muito diferente do mundo" - construção que permeia o imaginário de evangélicos, sempre ávidos por separar aquilo que faziam fora da igreja daquilo que dizem fazer após a conversão pois, em se tratando de escolha por uma candidatura, o que um evangélico "acorda" com sua liderança na igreja efetivamente se distancia muito do que faz quando está "no mundo", inclusive diante de uma urna, frustrando seriamente os planos dos que os pensam possuir.

\section{Considerações finais}

Terminada a eleição de 2014, e à luz dos dados oferecidos pela de 2010, é possível concluir que religião não pauta o voto no Brasil, sobretudo em se tratando do eleitorado evangélico, que é o que mais poderia servir de base para tal constatação, já que, como foi anteriormente mostrado, segundo a "visão geográfica do voto" de um dos seus mais importantes e influentes líderes, "o evangélico tem interação social, porque vai à igreja pelo menos uma vez por semana, e ninguém usa as redes sociais como os evangélicos".

Com mais uma acachapante derrota dos candidatos que seriam os preferidos pela liderança evangélica - lembrando que em 2014 o candidato pastor Everaldo não passou de $1 \%$ dos votos e Marina Silva nem chegou ao segundo turno, perdendo espaço para Aécio Neves - fica a confirmação de que, embora usufruam dos serviços e compartilhem dos princípios religiosos ensinados em seus espaços de culto e vivência da fé, os evangélicos não seriam tão afeitos a uma nova versão do voto de cabresto, contemplador da lógica que Leal (2012) chama de coronelismo, já que justificariam uma outra lógica, a surpreendente visão antropológica defensora de que "o povo sabe votar". (MAGALHÃES, 1998)

Não que votar no Partido dos Trabalhadores, vencedor dos dois pleitos aqui analisados, seja sinônimo de sabedoria ao votar, o que seria um juízo de valor que este trabalho não tem intenção $\mathrm{e}$ nem condição de fazer, mas porque o voto evangélico - ou religioso como um todo não segue a simplista lógica imposta até pouco tempo atrás pelos coronéis desta nação.

Assim, não por uma lógica baseada num conservadorismo radical, que não reflete o imaginário da maior parte do eleitorado, mas numa escolha racional, que mede, como quer Antony Downs(1999), os pacotes de benefícios oferecidos por cada candidato e partido, para só então escolher uma candidatura e decidir o voto, é que o religioso deverá ser visto enquanto eleitor. Já quanto à fala de Malafaia, que ameaçou os candidatos, dizendo: "cuidado, pois somos entre $25 \%$ e $27 \%$ da população", não resta outra coisa, à luz da resposta evangélica nas urnas, do que responder: “E...?!". 
Notas

1 Teólogo e Sociólogo. Mestre em Sociologia e Direito pelo PPGSD-UFF e Doutor em Sociologia pelo IESP-UERJ. Professor da Faculdade Unida de Vitória.

${ }^{2}$ http://revistaepoca.globo.com/Revista/Epoca/0EMI1 78504-15223,00-a+fe+entrou+na+campanha.html

${ }^{3}$ É bom lembrar, no entanto, que, se o fator religião e a tal ligação de Lula com a igreja católica (por conta das comunidades eclesiais de base, de cunho marxista) jamais teve o peso para decidir uma eleição, refutando o que apregoavam os evangélicos e o discurso de Collor.

4 http://www.amigodecristo.com/2010/10/jose-serraafirma-que-dilma-rousseff-esta-explorando-areligiao-na-politica.html

5 http://www.amigodecristo.com/2010/10/jose-serraafirma-que-dilma-rousseff-esta-explorando-areligiao-na-politica.html

http://www1.folha.uol.com.br/multimidia/videocasts/ 754535-veja-a-integra-da-sabatina-com-joseserra.shtml

7 http://www.amigodecristo.com/2010/10/apostolovaldemiro-santiago-participa-do-horario-eleitoralpedindo-votos-para-jose-serra.html

8 http://www.amigodecristo.com/2010/10/apostolovaldemiro-santiago-participa-do-horario-eleitoralpedindo-votos-para-jose-serra.html

9 http://www.amigodecristo.com/2010/10/apostolovaldemiro-santiago-participa-do-horario-eleitoralpedindo-votos-para-jose-serra.html

${ }^{10} \mathrm{http}: / /$ fabiosite.com.br/index.php?option=com_cont ent\&view=article\&id=2480:1ula-e-dilma-rousseffem- concentracao-de-fe-na-igreja-mundial-do-poder-dedeus-com-o-apostolo

valdemiro \&catid=60: noticias $\&$ Itemid $=1032$

http://www.institutoadediversidade.com.br/geral/batis tas-protestam-enquanto-dilma-visita-assembleia-dedeus/

12 Ibidem

Referências Bibliográficas

CAMPOS, Leonildo Silveira. Teatro, templo e mercado: organização e marketing de um empreendimento neopentecostal. Petrópolis: Vozes, 1997.

DOWNS, Anthony. Uma teoria econômica da democracia. São Paulo: Editora da Universidade de São Paulo, 1999.

HIRSCHMAN, Albert. A retórica da intransigência: perversidade, futilidade, ameaça. São Paulo: Cia. das letras, 1992.

LEAL, Victor Nunes. Coronelismo, enxada e voto. $4^{\mathrm{a}}$ ed. São Paulo: Cia. das letras, 2012.

MAGALHÃES Nara. $O$ povo sabe votar: uma visão antropológica. Petrópolis: Vozes/Unijuí, 1998.

PARUTY, Felipe \& PEROSA, Tereza. Entrevista. Silas Malafaia: 'Marina levará $80 \%$ dos votos evangélicos'. Entrevista. Revista Época. Set./2014.

SOUZA, Cleinton. Pauta não está na boca do povo. Entrevista. $\cos \boldsymbol{s} 2$ (9) (5) (6) Política. A gazeta. Vitória, out./2014.

; Religião, racismo e etnicidade. São Leopoldo RS: Oikos, 2010 
RELIGION AND POLITICS: THE EVANGELICAL WORLD AND THE

GEOGRAPHY OF THE VOTE

\begin{abstract}
THE PRESENT ARTICLE INTENTION IS TO MEASURE THE ELECTORAL WEIGHT OF THE "RELIGIOUS VOTE", WITH THE OBJECT OF ANALYSIS THE 2010 ELECTION, WHICH WAS VERY RICH ON THIS THEME, SERVING IT AS A BASE TO ALSO THINK ABOUT THE NEXT PRESIDENTIAL ELECTION, TO 2014. THE CENTRAL IDEA IS TO DIFFERENTIATE THE QUALITATIVE WEIGHT OF THE QUANTITATIVE WEIGHT OF THE RELIGIOUS VOTE, SINCE THE NUMBER OF INDIVIDUALS WHO ASCRIBE TO RELIGION THEIR ELECTORAL CHOICE PROVED TO BE VERY DIFFERENT FROM PRAYING THE SPEECH OF SOME SEGMENTS OF RELIGIOUS LEADERS, AND THAT THE FOCUS HERE IS THE TRAILER SPEECH TO THE SO-CALLED "EVANGELICAL VOTE" SO CHERISHED AND STRENGTHENED IN RELIGIOUS SPACES, YET SO LITTLE IN THE SECULAR SPHERE.
\end{abstract}

KEYWORDS: PRESIDENTIAL ELECTIONS; EVANGELICALS; RELIGIOUS VOW; SILAS MALAFAIA. 